\title{
Effect of ridge preservation for early implant placement - is there a need to remove the biomaterial?
}

Thoma, Daniel S ; Naenni, Nadja ; Benic, Goran I ; Muñoz, Fernando ; Hämmerle, Christoph H F ; Jung, Ronald E

\begin{abstract}
AIM To assess (i) bone regeneration around implants placed early in sites with or without ridge preservation and (ii) if the bone substitute material (DBBM-C) has to be removed at implant placement. MATERIALS AND METHODS In eight beagle dogs, three sites were randomly assigned to ridge preservation (DBBM-C plus collagen matrix (CMX)) (two sites; RP) or spontaneous healing (1 site; SH). Four weeks later, in one of the RP sites, dental implants were placed without removing the DBBM-C (RP1), whereas in RP2 and SH sites all nonintegrated DBBM-C and/or granulation tissue were removed before implant placement and concomitant GBR. Histomorphometric outcomes were assessed at 4 and 12 weeks. RESULTS The median buccal fBIC (first boneto-implant contact) was located more apical in groups RP1: $1.34 \mathrm{~mm}(0.09 ; 2.96)$ and RP2: $1.41 \mathrm{~mm}(0.54 ; 2.72)$ than in group SH: $0.79 \mathrm{~mm}(0.26 ; 1.50)(\mathrm{p}=0.452)$ at 4 weeks. At 12 weeks, median buccal fBIC values were for RP1: $0.88 \mathrm{~mm}(0.00 ; 2.33)$, for RP2: $0.16 \mathrm{~mm}(0.00 ; 1.33)$ and for SH: $0.00 \mathrm{~mm}(0.00 ; 0.98)(\mathrm{p}=0.362)$. BIC values increased over 12 weeks in all groups. CONCLUSIONS Ridge preservation followed by early implant placement led to higher BIC values at 12 than at 4 weeks. There is no need to remove the biomaterial at implant placement to ensure osseointegration. No relevant differences were observed between the three groups for any outcome measure.
\end{abstract}

DOI: https://doi.org/10.1111/jcpe.12709

Posted at the Zurich Open Repository and Archive, University of Zurich ZORA URL: https://doi.org/10.5167/uzh-136863

Journal Article

Accepted Version

Originally published at:

Thoma, Daniel S; Naenni, Nadja; Benic, Goran I; Muñoz, Fernando; Hämmerle, Christoph H F; Jung, Ronald E (2017). Effect of ridge preservation for early implant placement - is there a need to remove the biomaterial? Journal of Clinical Periodontology, 44(5):556-565.

DOI: https://doi.org/10.1111/jcpe.12709 
Effect of ridge preservation for early implant placement - is there a need to remove the biomaterial?

Running Title: early implant placement

Daniel S. Thoma ${ }^{1}$, Nadja Naenni ${ }^{1}$, Goran I. Benic ${ }^{1}$, Fernando Munoz ${ }^{2}$, Christoph H. F.

Hämmerle $^{1}$, Ronald E. Jung ${ }^{1}$

${ }^{1}$ Clinic of Fixed and Removable Prosthodontics and Dental Material Science, Center for Dental Medicine, University of Zurich, Zurich, Switzerland

${ }^{2}$ Department of Veterinary Clinical Sciences, University of Santiago de Compostela, Lugo, Spain

Key words: ridge preservation, volume stability, alveolar ridge augmentation (MeSH)

Address for correspondence: $\quad$ PD Dr. Daniel S. Thoma

Clinic of Fixed and Removable Prosthodontics and

Dental Material Science

Center of Dental Medicine, University of Zurich

Plattenstrasse 11

CH-8032 Zurich, Switzerland

Phone: +41 446343260

Fax: +41 446344305

E-mail: daniel.thoma@zzm.uzh.ch 


\begin{abstract}
Aim: to assess i) bone regeneration around implants placed early in sites with or without ridge preservation and i) if the bone substitute material (DBBM-C) has to be removed at implant placement
\end{abstract}

Materials and methods: In eight beagle dogs, three sites were randomly assigned to ridge preservation (DBBM-C plus collagen matrix (CMX)) (two sites; RP) or spontaneous healing (1 site; SH). Four weeks later, in one of the RP sites, dental implants were placed without removing the DBBM-C (RP1), whereas in RP2 and SH sites all non-integrated DBBM-C and/or granulation tissue was removed before implant placement and concomitant GBR. Histomorphometric outcomes were assessed at 4 and 12 weeks.

Results: The median buccal fBIC (first bone-to-implant contact) was located more apical in groups RP1: $1.34 \mathrm{~mm}(0.09 ; 2.96)$ and RP2: $1.41 \mathrm{~mm}(0.54 ; 2.72)$ than in group SH: $0.79 \mathrm{~mm}$ $(0.26 ; 1.50)(\mathrm{p}=0.452)$ at 4 weeks. At 12 weeks, median buccal fBIC values were for RP1: $0.88 \mathrm{~mm}(0.00 ; 2.33)$, for RP2: $0.16 \mathrm{~mm}(0.00 ; 1.33)$ and for SH: $0.00 \mathrm{~mm}(0.00 ; 0.98)$ $(p=0.362)$. BIC values increased over 12 weeks in all groups.

Conclusions: Ridge preservation followed by early implant placement led to higher BIC values at 12 than at 4 weeks. There is no need to remove the biomaterial at implant placement to ensure osseointegration. No relevant differences were observed between the three groups for any outcome measure. 


\section{Clinical Relevance}

Scientific rationale for the study: Alveolar ridge preservation procedures are frequently performed rendering similar implant survival rates as implants placed in native bone. Disadvantages include a relatively long healing time prior to implant placement to allow for maturation of the bone graft material. Early implant placement following ridge preservation has not been investigated so far.

Principal findings: Ridge preservation using DBBM-C and a CMX followed by early implant placement leads to higher BIC values at 12 weeks than at 4 weeks. There is no need to remove the biomaterial at implant placement to ensure osseointegration.

Practical implications: Alveolar ridge preservation appears to allow for early implant placement without the need to remove the biomaterial at the day of implant placement rendering similar histologic outcomes based on a preclinical model. 


\section{Introduction}

A number of preclinical and clinical studies have documented that after tooth extraction a mean resorption of the buccal bone contour of approximately $50 \%$ is taking place within the first 4-6 months (Schropp et al., 2003, Tan et al., 2012, Jung et al., 2013, Atwood, 2001, Tallgren, 1972). This might have a significant clinical impact by hampering implant placement without additional bone augmentation procedures and may also result in inadequate esthetic outcomes due to ridge deficiencies.

Current clinical studies evaluated the effect of different alveolar ridge preservation techniques to overcome the resorption process after tooth extraction (Vignoletti et al., 2012, Jung et al., 2013). These data are based on clinical studies reporting that the use of slowly resorbing grafting materials with a flap closure or a sealing towards the oral cavity result in significant less horizontal and vertical resorption after tooth extraction compared to spontaneous healing. The criticism of these techniques is the fact that they delay the overall treatment time because implant placement is taking place at least 4-6 months after tooth extraction. Hence, there is a high clinical interest in evaluating early implant placement into sites that had previously undergone alveolar ridge preservation procedures.

A histomorphometric study in humans revealed marked de novo bone formation after a healing period of 6 weeks (Heberer et al., 2008) following tooth extraction and alveolar ridge preservation. This study reported a mean overall new bone formation of $28 \%$ (range $9 \%-$ $57 \%$ ) after 6 weeks of healing. It was concluded that the application of the graft material into the extraction socket does not hinder early bone formation. Early implant placement into a healing alveolar socket previously treated with ridge preservation has not been evaluated so far. One might speculate that early implant placement disturbs the healing processes within the augmented alveolar sockets if the biomaterial is not removed.

The aim of the present study was to evaluate bone regeneration around implants placed early in sites i) with ridge preservation and without removal of the DBBM material, ii) with ridge 
preservation, with removal of the DBBM material and concomitant guided bone regeneration and iii) with spontaneous healing and concomitant GBR.

\section{Materials and Methods}

\section{Animals}

This study was designed as a randomized experimental study employing 8 male beagle dogs (Isoquimen, Barcelona, Spain). At the beginning, the animals had a mean age of 21 months (range 16 to 24 ) and a mean weight of $17.30 \mathrm{~kg}$ (range 15.00 to $20.85 \mathrm{~kg}$ ). The study was performed at the animal facility of the Rof Codina Foundation (Lugo, Spain) according to the guidelines of the Spanish and European regulations about care and use of research animals. Prior to the beginning of the study, the experimental protocol was approved by the local ethical committee (Protocol AELU001/14/INVMED/OUTROS(04)/FMG/04) and the manuscript has been written according to the ARRIVE guidelines (Kilkenny et al., 2010) . The animals were kept in a group kennel with indoor and outdoor areas, fed with a granulated dog food previously wetted in water and had free access to tap water. The experiment was carried out from March to November 2014.

\section{Surgical procedures}

All surgical procedures were performed under general anesthesia in an operating room and under sterile conditions. On the day of surgery, the dogs were premedicated with medetomidine (0.020 mg/kg, intramusculary, Domtor; Esteve, Barcelona, Spain) and morphine $(0.5 \mathrm{mg} / \mathrm{kg}$ intramusculary, Morfina Braun 2\%; B. Braun Medical, Barcelona, Spain). Subsequently, general anesthesia was induced by injection of propofol $(3-5 \mathrm{mg} / \mathrm{kg}$ intravenously, Propovet, Abbott Laboratories, Kent, UK). Isofluorane (2.5-4\%; Isoba-Vet; Schering-Plough, Spain) and O2 (100\%) were used as inhalated anesthetics.

Postoperative pain was controlled with morphine $(0.2 \mathrm{mg} / \mathrm{kg} / \mathrm{i} . \mathrm{m} . / 6 \mathrm{~h}$, Morfina Braun 2\%; B. Braun Medical, Spain) and meloxicam (0.2 mg/kg/i.m./SID, Metacam; Boehringer 
Ingelheim, Spain) during 5 days. Prophylactic administration of cefazolin (20 $\mathrm{mg} / \mathrm{kg} /$ s.c./SID, Kurgan; Normon, Spain) and cefovecin (8 mg/kg/s.c./SID, Convenia; Zoetis, Spain) was performed intraoperatively. The oral mucosa and the teeth were disinfected three times a week by using gauzes soaked in a $0.12 \%$ chlorhexidine solution (Perio-Aid Tratamiento_, Dentaid, Barcelona, Spain). Subsequently, a toothbrush and a $0.2 \%$ chlorhexidine gel (Chlorhexidine Bioadhesive Gel, Lacer, Barcelona, Spain) were used for plaque control.

\section{Extractions}

After disinfection of the surgical site with $0.2 \%$ chlorhexidine solution (Corsodyl, GlaxoSmithKline, Brentford, Middlesex, UK), local anesthetics (Lidocaine $\mathrm{HCl}$ 2\% with epinephrine 1:100`000; Henry Schein Inc., Port Washington, NY, USA) were administered by infiltration at the respective buccal and lingual sites (Fig. 1A). On one side of the mandible in all dogs (side randomly assigned), the mesial root of M1, the mesial root of P4 and the mesial root of P3 were extracted without raising a flap (Fig. 1B). All buccal bone plates were left intact. Root canal treatment was performed for the distal root of M1, the distal root of P4 and the distal root of P3 (Fig. 1C) (Thoma et al., 2010).

\section{Ridge preservation procedures}

The following three treatment modalities were randomly applied to the three extraction sockets (the mesial root of M1, the mesial root of P4 and the mesial root of P3):

○ ridge preservation (RP 1 sites): xenogeneic bone substitute with $10 \%$ collagen (DBBM-C; Geistlich Bio-Oss ${ }^{\circledR}$ Collagen, Geistlich Pharma AG, Wolhusen, Switzerland $)+$ xenogeneic collagen matrix $\left(\right.$ CMX; Geistlich Mucograft ${ }^{\circledR}$ Seal, Geistlich Pharma AG, Wolhusen, Switzerland)

- ridge preservation ( $\mathrm{RP} 2$ sites): $\mathrm{DBBM}-\mathrm{C}+\mathrm{CMX}$

- no further treatment ( $\mathrm{SH}$ sites) 
The DBBM-C was placed up to the level of the bone crest in groups RP1 and RP2 (Fig. 1D). The CMX was sutured epigingivally on top of the DBBM-C using non-resorbable sutures (Dafilon 6-0, Braun). No sutures were used for SH sites (Fig. 1E).

Four weeks later, implant placement was performed in all these sites (Fig. 2A). For that purpose, muco-periosteal flaps were elevated (Fig. 2B) and dental implants placed with the implant shoulder positioned flush with the buccal bone crest and slightly lingual to the center of the original extraction socket. In RP1 sites, implants were placed without further bone augmentation; in RP2 and SH sites, all DBBM-C material and/or granulation tissue was carefully removed (Fig. 2C) and dental implants placed (Fig. 2D\&E). In these two groups (RP2, SH), peri-implant defects were augmented using deproteinized bovine bone particles (Geistlich Bio-Oss ${ }^{\circledR}$, Geistlich Pharma AG, Wolhusen, Switzerland) (Fig. 2F) and covered with a native collagen membrane (Geistlich Bio-Gide ${ }^{\circledR}$, Geistlich Pharma AG, Wolhusen, Switzerland) (Fig. 2G). The sites were not over-augmented and the augmentation did not exceed the original bucco-oral ridge width. Resorbable pins were used to stabilize the membranes and the augmented area in the apical region. Subsequently, periosteal releasing incisions were performed and flaps closed tension-free in all sites (Fig. 2H). Seven days later, the dogs were briefly anesthetized, sutures removed, the mucosa and the teeth cleaned. Four weeks later, tooth extractions and ridge preservation procedures were performed in all so far untreated sides of the mandible. Another four weeks later, implant placement was performed in all these sides and sites. The procedures for tooth extraction, ridge preservation and implant placement were similar to what has been described above (Fig. 3).

\section{Sacrifice}

Four weeks after the final surgeries, all dogs were painlessly sacrificed using an overdose of pentobarbital (60 mg/kg/i.v., Dolethal; Vetoquinol, France) after sedation with medetomidine $(0.030 \mathrm{mg} / \mathrm{kg} / \mathrm{i} . \mathrm{m}$.$) , thereby rendering endpoints of 4$ and 12 weeks of healing following implant placement. 
Implants and surrounding soft tissues were macroscopically inspected. Any local inflammation, necrosis, hemorrhage, dehiscence or any other lesion were recorded. Following dissection, the 2 hemi-mandibles were block resected and fixed in buffered $10 \%$ formaldehyde solution and implants individually separated using a band saw.

\section{Histologic preparation}

The 48 sites ( 6 per animal) were dehydrated in a series of graded alcohol solutions and embedded in a light-curing resin (Technovit 7200 VLC; Heraeus-Kulzer GMBH, Werheim, Germany). From each specimen, one central bucco-lingual section through the defect/augmented site were prepared for histological assessment by a microcutting and grinding technique adapted by Donath (Donath and Breuner, 1982). Thereafter, the sections were stained with Levai-Laczkó (Laczkò and Lévai, 1975).

\section{Analyses}

\section{General wound healing}

The wound healing was analyzed descriptively at the day of implant placement: complete/incomplete (dehiscence) wound closure at the implant sites.

\section{Histomorphometric analyses}

Computer-assisted histomorphometric measurements were performed using an automated image analysis system (CellSens dimensions, Olympus Corporation, Tokyo, Japan), coupled with a video camera (DP71, Olympus, Japan) mounted on a motorized light microscope (BX51, Olympus, Japan). All measurements were performed by one calibrated and masked examiner (FM). The analyses included the following landmarks, distances and tissue components (Fig. 4A):

- the first bone to implant contact (mm; fBIC), measured from the implant shoulder to the first bone to implant contact on the buccal $\left(\mathrm{fBIC}_{\mathrm{b}}=\right.$ primary endpoint $)$ and lingual $\left(\mathrm{fBIC}_{\mathrm{l}}\right)$ side

- the bone-to-implant contact along the implant surface (BIC; \%) 
- the vertical distance between the bone crest and the implant shoulder on the buccal $\left(\mathrm{B}_{\mathrm{b}}\right)$ and lingual $\left(\mathrm{B}_{\mathrm{l}}\right)$ side

- estimated ridge profile (mm2; ERP);

- estimated regenerated area (mm2; ERA);

- percentage of estimated regenerated area within estimated ridge profile $(\%$;

\section{ERA/ERP)}

- percentages of new bone, lamellar bone (old bone), bone substitute material and non-mineralized tissue within ERP (\%)

The estimated defect area (ERP) represented the estimated (physiologic) ridge profile vertically (from the bone crest/implant shoulder and 4mm more apically) and horizontally (from the implant surface to the buccal bone plate) on the buccal side of the implants. The estimated regenerated area (ERA) represented the obtained ridge profile encompassing a region with the following borders: vertical ( $4 \mathrm{~mm}$ apical of the implant shoulder to the most coronal location of bone/bone substitute material) and horizontal (implant surface to the most buccal location of bone/bone substitute material (Fig. 4a) (Thoma et al., 2012).

\section{Statistical analysis}

Mean, median, standard deviation and the range as well as counts and percentages were used to describe continuously and categorically scaled variables, respectively. The unit of analysis was the site since the two sides in each dog were operated at different time-points. The comparison of the treatments and possible confounding factors were analyzed with nonparametric mixed models because of the dependent data and the non-normality of the data. The primary endpoint was $\mathrm{fBIC}_{\mathrm{b}}$. In case of a significant result, pairwise comparisons were applied with the Wilcoxon signed-rank test with Bonferroni correction. Also, the side and site factors were analyzed in the same way as possible confounding factors. For the primary endpoint, nonparametric $95 \%$ confidence intervals were derived for the medians. 


\section{Results}

\section{Healing}

General healing in all dogs was uneventful and no local infections were observed. In all premolar and $75 \%$ of the molar sites, the soft tissues were completely closed at the time of implant placement. No differences between RP and SH sites were detected for the remaining $25 \%$ of molar sites that presented an incomplete healing with minor soft tissue dehiscences.

\section{Histomorphometric analyses (Fig.4 b-g) (Table 1)}

The median buccal $\mathrm{fBIC}$ was located more apical in the two ridge preservation groups RP1 (1.34mm, $95 \%$ confidence interval (c.i.) $(0.0 ; 5.89))$, RP2 (1.41mm, 95\% c.i. $(0.0 ; 6.17))$ than in group $\mathrm{SH}(0.79 \mathrm{~mm}, 95 \%$ c.i. $(0.0 ; 4.92))(\mathrm{p}=0.452)$ at 4 weeks. At 12 weeks, $\mathrm{fBIC}_{\mathrm{b}}$ values were $0.88 \mathrm{~mm}(\mathrm{RP} 1,95 \%$ c.i. $(0.0 ; 6.50)), 0.16 \mathrm{~mm}(\mathrm{RP} 2,95 \%$ c.i. $(0.0 ; 1.81))$ and $0 \mathrm{~mm}(\mathrm{SH}$, $95 \%$ c.i. $(0.0 ; 1.61))(\mathrm{p}=0.362)$. The side and the site effect was not significant for this endpoint.

BIC values were, in general, higher at 12 weeks than at 4 weeks and higher on the lingual than on the buccal side. One the buccal side, at 4 weeks, $\mathrm{BIC}_{\mathrm{b}}$ ranged between $61.9 \%(\mathrm{RP} 1)$ and $71.4 \%(\mathrm{SH})$, whereas at 12 weeks, $\mathrm{BIC}_{\mathrm{b}}$ ranged between $75.4 \%(\mathrm{RP} 2)$ and $84.3 \%(\mathrm{SH})$. The distance between the bone crest and the implant shoulder on the buccal side $\left(\mathrm{B}_{\mathrm{b}}\right)$ was minimal in all groups with median values for RP1 of $-0.02 \mathrm{~mm}(-2.19 ; 0.94)$, for RP2 of $0.88 \mathrm{~mm}(0.17 ; 1.15)$ and for SH of $0.42 \mathrm{~mm}(-0.71 ; 0.73)$ at 4 weeks $(\mathrm{p}=0.198)$ demonstrating that the implants were placed flush with the buccal bone plate and only minimal changes of the buccal bone had taken place. At 12 weeks, the bone crest was located closer to the implant shoulder level with median values for RP1 of $-0.04 \mathrm{~mm}(-1.74 ; 1.27)$, for RP2 of $0.04 \mathrm{~mm}(-$ $2.18 ; 0.29)$ and for SH of $-0.88 \mathrm{~mm}(-1.15 ; 0.48)(\mathrm{p}=0.726)$ compared to the 4 -week timepoint. 
The median relative augmented area (ERP/ERA) was similar in all groups and at both timepoints ranging between 106.3\% (Q1: 83.7; Q3: 120.6) (SH) and 122.2\% (100.0; 176.9) (RP1) (4 weeks) and between 104.8\% (77.1; 118.7) (SH) and 108.7\% (100.0; 122.0) (RP2) (12 weeks). Inter-group comparisons were not significantly different ( 4 weeks: $p=0.476 ; 12$ weeks: $p=0.892$ ). Median ERA values exceeded median ERP values resulting in median ERP/ERA values above $100 \%$ in all groups and at both time-points (Fig. 4g). Within the region of interest (ERP), none of the comparisons did reveal any statistically significant differences between the groups at 4 and 12 weeks. The median amount of newly formed bone ranged between $32.8 \%(21.5 ; 39.3)(\mathrm{RP} 1)$ and $42.2 \%(26.9 ; 48.4)(\mathrm{SH})(4$ weeks) $(\mathrm{p}=0.379)$ and between $51.6 \%(47.7 ; 60.4)(\mathrm{RP} 2)$ and $56.7 \%(39.3 ; 65.0)(\mathrm{RP} 1)(12$ weeks $)(\mathrm{p}=0.650)$.

None of the inter-group comparisons did reveal any statistically significant differences and neither the confounding factor "side" did influence the treatment outcomes significantly. The factor "site", however, did influence the outcomes significantly for a number of parameters. This included at 4 weeks: the level of the buccal $\left(B_{b} ; p=0.007\right)$ and lingual bone crest $\left(B_{1}\right.$; $\mathrm{p}=0.001)$, BIC values on the lingual side $\left(\mathrm{BIC}_{1} ; \mathrm{p}=0.006\right)$ as well as the amount of lamellar bone $(p=0.010)$ and bone substitute material $(p=0.002)$. Similar data for 12 weeks were: the level of the buccal $\left(B_{b} ; p=0.001\right)$ and lingual bone crest $\left(B_{l} ; p=0.000\right)$, the relative augmented area $(\mathrm{ERP} / \mathrm{ERA} ; \mathrm{p}=0.002)$ and the amount of bone substitute material $(\mathrm{p}=0.002)$. These data demonstrated less favorable treatment outcomes for the described parameters and time-points for all groups in $\mathrm{P} 3$ sites compared to $\mathrm{P} 4$ and $\mathrm{M} 1$ sites.

\section{Discussion}

The present experimental study revealed i) that early implant placement into sites treated with ridge preservation (RP1) does not interfere with the bone healing process, ii) no necessity to 
remove the biomaterial in a healing extraction socket to ensure osseointegration of dental implants, iii) that early implant placement into sites previously treated with ridge preservation results in higher BIC and $\mathrm{fBIC}$ values at 12 than at 4 weeks, but similar to sites previously subjected to spontaneous healing and, iv) that the combination of ridge preservation and subsequent implant placement with GBR is not superior to spontaneously healing sites followed by implant placement and concomitant GBR.

Ridge preservation procedures demonstrated to be successful in maintaining the ridge profile and reducing the amount of resorption following tooth extraction in a plethora of studies using various materials and techniques (Vignoletti et al., 2012). Based on one recent systematic review, limited evidence was found demonstrating improved implant-related outcomes following ridge preservation procedures and compared to spontaneous healing. Benefits, however, were observed in terms of the need for further bone augmentation at the day of implant placement (Mardas et al., 2015). This to some extent surprising conclusion mainly derives from the fact that only few studies exist, documenting further clinical benefits of ridge preservation procedures compared to spontaneously healing in terms of implant survival, marginal bone loss, necessity of further grafting procedures or patient-reported outcome measures (Spinato et al., 2014, Barone et al., 2012, Barone et al., 2013). Moreover, due to the placement of a bone grafting material within the socket, often in combination with an autogenous graft/soft tissue substitute material or a membrane on top, healing times are proposed to be at least 4 months prior to implant placement. In the light of simplifying clinical procedures, reducing healing times, counteracting resorptive processes and reducing the need for augmentation procedures at the day of implant surgery, the time-point of implant placement following ridge preservation procedures is crucial. The present study clearly demonstrated that early implant placement does not interfere with a healing socket previously treated with a bone substitute material. This was demonstrated by more bone formation within the region of interest, a relative augmented area (ERP/ERA) similar or slightly exceeding the 
original ridge profile ( $\geq 100 \%)$ and a first bone to implant contact closer to the implant shoulder at 12 compared to 4 weeks. No significant differences were observed between sites without removal of the biomaterial (RP1) and sites receiving further GBR at implant placement (RP2). RP1 sites, however, demonstrated a larger confidence interval. Based on these outcomes, early implant placement following ridge preservation without removal of the biomaterial has to be further investigated. The procedure is limited to extraction sites exhibiting a fully intact buccal bone plate and supported by preclinical data only. Since no clinical studies are available so far and the present study was performed in a preclinical setting, no clinical recommendations can be made. The treatment strategy, however, would offer benefits for clinicians: reduced healing time prior to implant placement, an easier surgical intervention at implant placement (no GBR necessary) and maintenance of the ridge contour. From a patient's perspective, this approach not only saves time (earlier implant placement) and costs (no further GBR), but should also reduce the invasiveness of the surgery. Keeping in mind that this ridge preservation procedure successfully maintains the ridge contour, there will be no need to raise an extensive flap for implant placement. The BIC values observed in this study were higher on the lingual than on the buccal side at the early time-point. At 12 weeks, buccal BIC values were higher than at 4 weeks and similar to the lingual ones. Moreover, minimal differences were observed between the three treatment modalities. The early healing time-point revealed the greatest differences between buccal and lingual BIC values. This observation might be due to a greater peri-implant defect and more biomaterial present on the buccal compared to the lingual side. Moreover, as stated above, the placement of a dental implant into a site with a healing biomaterial did not counteract the healing process as demonstrated by BIC values being not significantly different between the two RP groups and the SH group. Xenografts were placed in extraction sites for ridge preservation procedures in various studies (Artzi et al., 2000, Barone et al., 2008, Cook and Mealey, 2013). In these studies, biopsies were obtained at the day of implant placement, 
therefore not analyzing bone formation along the implant surfaces. According to animal experiments, DBBM-C has shown to act as a scaffold for tissue formation during healing time-points of 3 and 6 months and to limit the dimensional changes of the ridge following tooth extraction compared to sites healing spontaneously (Araujo and Lindhe, 2009). The latter outcome could not be corroborated in the present study. RP and SH sites presented similar ridge dimensions at both sacrifice time-points. One has to bear in mind, however, that in SH sites, GBR was performed at the day of implant placement. The effect of GBR could not be assessed due to the lack of a further control group (spontaneous healing without GBR). The amount of residual biomaterial particles (ranging between $2 \%$ and $7 \%$ at 12 and 4 weeks following implant placement and 16 and 8 weeks after ridge preservation), was considerably lower than compared to previous studies in humans with remaining DBBM(-C) ranging between 13\% and 38\% with healing times of 4-6 months (Nart et al., 2016, Lee et al., 2009, Cook and Mealey, 2013). Again, the main difference is that in the present study, dental implants were placed, thereby removing a greater part of the biomaterial at the day of implant placement. Scientific preclinical evidence for implants placed following ridge preservation procedures is scarce in the literature. In a majority of the studies, immediate implants in combination with ridge preservation or lateral ridge augmentation with subsequent implant placement were evaluated (von Arx et al., 2001, Pereira et al., 2016, Caneva et al., 2012). In one experimental study in dogs, dental implants were placed 8 weeks after ridge preservation of enlarged defects. Bone-to-implant contact values were higher in ridge preservation sites compared to untreated sites. The study design, however, demonstrates two critical differences compared to the present study: delayed implant placement and no GBR at implant placement (Shi et al., 2007).

Alveolar ridge preservation procedures, focusing on the soft tissue level, mainly aim to enhance the missing soft tissue quality and/or regenerate the quantity of soft tissue. Available options thereby include the use of an autogenous subepithelial connective tissue graft 
(SCTG), a soft tissue substitute or a resorbable membrane to enhance soft tissue wound closure (Tal, 1999, Jung et al., 2004, Barone et al., 2015, Sisti et al., 2012, Stimmelmayr et al., 2012, Stimmelmayr et al., 2010). The healing period for such an intervention is kept to 6-8 weeks and the autogenous soft tissue graft appears to be the most suitable graft to optimize the ridge profile on the soft tissue level (Thoma et al., 2014, Thoma et al., 2009). The present preclinical study is one of the first to document the early healing phase on the soft tissue level using a collagen matrix as a soft tissue substitute to allow for early implant placement. No benefit of ridge preservation was observed on the soft tissue level at the day of implant placement compared to sites with spontaneous healing. This is in line with previous reports for spontaneous healing or using a collagen matrix as socket seal following a longer healing period (Jung et al., 2013, Roman et al., 2015, Lindhe et al., 2014).

The proposed approach, being derived and supported by a preclinical experiment, might be regarded with caution. Further well-designed clinical trials need to be performed. Moreover, indications are currently limited to extraction sites with a fully intact buccal bone plate and restricted to premolar sites with a sufficient distance between the buccal implant shoulder and the bone crest. This was underlined by $\mathrm{P} 3$ sites demonstrating a significantly more unfavorable outcome (compared to P4 and M1 sites) for a number of parameters (see above). In addition, $25 \%$ of the molar sites did not show a complete soft tissue healing. The calculation of ERA/ERP demonstrated median values exceeding $100 \%$ at both time-points. This revealed a high wound healing capacity in the present experimental setting with intact buccal bone plates and sites demonstrating buccal bone formation in a vertical direction (above the implant shoulder). Such outcomes might rarely be observed in patients. Moreover, no baseline data (ideal ridge profile) were available and histologic outcomes were assessed at two time-points encompassing different animals. From a methodological point of view, these time-points reflect endpoint measures and did not allow assessing the dynamic of the healing over time. One might also speculate that the physiologic ridge profile was underestimated in 
the present study. Early implant placement in sites following ridge preservation and without removal of the bone substitute material, therefore, did not show a clinical benefit on the hard tissue level (width of the ridge) as well as on the soft tissue level (soft tissue healing) as compared to early implant placement in sites following spontaneous healing. Even though, no significant differences were observed for the primary outcome " $\mathrm{ABIC}_{\mathrm{b}}$ " between the groups, RP1 sites demonstrated the largest confidence interval. This strongly suggests that more research is needed on a preclinical level encompassing a more stringent protocol with more standardized sites and even a longer observation period. Clinically, future research should be directed towards studies on early implant placement into sites with or without previous ridge preservation in order to evaluate potential benefits for clinicians and patients over time.

\section{Conclusions}

Ridge preservation using a xenogeneic bone substitute material (DBBM-C) and a xenogeneic collagen matrix (CMX) as socket seal followed by early implant placement led to a complete soft tissue wound healing in premolar sites, higher BIC and smaller fBIC values at 12 than at 4 weeks. There was no necessity observed to remove the biomaterial at the day of implant placement to ensure osseointegration at 12 weeks. No relevant differences between the treatment modalities were observed for any of the assessed outcomes. 


\section{Acknowledgements and Conflict of Interest}

The authors would like to acknowledge Prof. Dr. Jürg Hüsler (for his support in the statistical analysis of the data) and Dr. Francine Brandenberg (for performing part of the surgeries), both Clinic of Fixed and Removable Prosthodontics and Dental Material Science, Center of Dental Medicine, University of Zurich, Zurich, Switzerland. The support and help of the animal care team at the Facultad de Veterinaria, Campus Universitario s/n, Lugo, Spain is greatly appreciated. This study was funded by the Clinic of Fixed and Removable Prosthodontics and Dental Material Science, Center of Dental Medicine, University of Zurich, Zurich, Switzerland and by a research grant of Geistlich Pharma AG, Wolhusen, Switzerland. The authors report no conflict of interest for this study. 


\section{References}

Araujo, M. G. \& Lindhe, J. (2009) Ridge preservation with the use of Bio-Oss collagen: A 6-month study in the dog. Clin Oral Implants Res 20, 433-440. doi: $10.1111 / \mathrm{j} .1600-0501.2009 .01705 . x$.

Artzi, Z., Tal, H. \& Dayan, D. (2000) Porous bovine bone mineral in healing of human extraction sockets. Part 1: histomorphometric evaluations at 9 months. $J$ Periodontol 71, 1015-1023. doi:10.1902/jop.2000.71.6.1015.

Atwood, D. A. (2001) Some clinical factors related to rate of resorption of residual ridges. 1962. J Prosthet Dent 86, 119-125.

Barone, A., Aldini, N. N., Fini, M., Giardino, R., Calvo Guirado, J. L. \& Covani, U. (2008) Xenograft versus extraction alone for ridge preservation after tooth removal: a clinical and histomorphometric study. J Periodontol 79, 1370-1377. doi:10.1902/jop.2008.070628.

Barone, A., Borgia, V., Covani, U., Ricci, M., Piattelli, A. \& Iezzi, G. (2015) Flap versus flapless procedure for ridge preservation in alveolar extraction sockets: a histological evaluation in a randomized clinical trial. Clin Oral Implants Res 26, 806-813. doi:10.1111/clr.12358.

Barone, A., Orlando, B., Cingano, L., Marconcini, S., Derchi, G. \& Covani, U. (2012) A randomized clinical trial to evaluate and compare implants placed in augmented versus non-augmented extraction sockets: 3-year results. J Periodontol 83, 836846. doi:10.1902/jop.2011.110205.

Barone, A., Ricci, M., Tonelli, P., Santini, S. \& Covani, U. (2013) Tissue changes of extraction sockets in humans: a comparison of spontaneous healing vs. ridge preservation with secondary soft tissue healing. Clin Oral Implants Res 24, 12311237. doi:10.1111/j.1600-0501.2012.02535.x.

Caneva, M., Botticelli, D., Pantani, F., Baffone, G. M., Rangel, I. G., Jr. \& Lang, N. P. (2012) Deproteinized bovine bone mineral in marginal defects at implants installed immediately into extraction sockets: an experimental study in dogs. Clin Oral Implants Res 23, 106-112. doi:10.1111/j.1600-0501.2011.02202.x.

Cioban, C., Zaganescu, R., Roman, A., Muste, A., Beteg, F., Campian, R. S. \& Bosca, B. (2013) Early healing after ridge preservation with a new collagen matrix in dog extraction sockets: preliminary observations. Rom J Morphol Embryol 54, 125130.

Cook, D. C. \& Mealey, B. L. (2013) Histologic comparison of healing following tooth extraction with ridge preservation using two different xenograft protocols. $J$ Periodontol 84, 585-594. doi:10.1902/jop.2012.120219.

Donath, K. \& Breuner, G. (1982) A method for the study of undecalcified bones and teeth with attached soft tissues. The Sage-Schliff (sawing and grinding) technique. $J$ Oral Pathol 11, 318-326. 
Heberer, S., Al-Chawaf, B., Hildebrand, D., Nelson, J. J. \& Nelson, K. (2008) Histomorphometric analysis of extraction sockets augmented with Bio-Oss Collagen after a 6-week healing period: a prospective study. Clin Oral Implants Res 19, 1219-1225. doi:10.1111/j.1600-0501.2008.01617.x.

Jung, R. E., Philipp, A., Annen, B. M., Signorelli, L., Thoma, D. S., Hammerle, C. H., Attin, T. \& Schmidlin, P. (2013) Radiographic evaluation of different techniques for ridge preservation after tooth extraction: a randomized controlled clinical trial. $J$ Clin Periodontol 40, 90-98. doi:10.1111/jcpe.12027.

Jung, R. E., Siegenthaler, D. W. \& Hammerle, C. H. (2004) Postextraction tissue management: a soft tissue punch technique. Int J Periodontics Restorative Dent 24, 545-553.

Kilkenny, C., Browne, W. J., Cuthill, I. C., Emerson, M. \& Altman, D. G. (2010) Improving bioscience research reporting: the ARRIVE guidelines for reporting animal research. PLoS Biol 8, e1000412. doi:10.1371/journal.pbio.1000412.

Laczkò, J. \& Lévai, G. (1975) A simple differential staining method for semi-thin sections of ossifying cartilage and bone tissues embedded in epoxy resin. Mikroskopie Bd. 31S, 1-4.

Lee, D. W., Pi, S. H., Lee, S. K. \& Kim, E. C. (2009) Comparative histomorphometric analysis of extraction sockets healing implanted with bovine xenografts, irradiated cancellous allografts, and solvent-dehydrated allografts in humans. Int J Oral Maxillofac Implants 24, 609-615.

Lindhe, J., Cecchinato, D., Donati, M., Tomasi, C. \& Liljenberg, B. (2014) Ridge preservation with the use of deproteinized bovine bone mineral. Clin Oral Implants Res 25, 786-790. doi:10.1111/clr.12170.

Mardas, N., Trullenque-Eriksson, A., MacBeth, N., Petrie, A. \& Donos, N. (2015) Does ridge preservation following tooth extraction improve implant treatment outcomes: a systematic review: Group 4: Therapeutic concepts \& methods. Clin Oral Implants Res 26 Suppl 11, 180-201. doi:10.1111/clr.12639.

Nart, J., Barallat, L., Jimenez, D., Mestres, J., Gomez, A., Carrasco, M. A., Violant, D. \& Ruiz-Magaz, V. (2016) Radiographic and histological evaluation of deproteinized bovine bone mineral vs. deproteinized bovine bone mineral with $10 \%$ collagen in ridge preservation. A randomized controlled clinical trial. Clin Oral Implants Res. doi:10.1111/clr.12889.

Pereira, F. P., De Santis, E., Hochuli-Vieira, E., de Souza Faco, E. F., Pantani, F., Salata, L. A. \& Botticelli, D. (2016) Deproteinized Bovine Bone Mineral or Autologous Bone at Dehiscence Type Defects at Implants Installed Immediately into Extraction Sockets: An Experimental Study in Dogs. Clin Implant Dent Relat Res 18, 507-516. doi:10.1111/cid.12328. 
Roman, A., Cioban, C., Stratul, S. I., Schwarz, F., Muste, A., Petrutiu, S. A., Zaganescu, R. \& Mihatovic, I. (2015) Ridge preservation using a new 3D collagen matrix: a preclinical study. Clin Oral Investig 19, 1527-1536. doi:10.1007/s00784-0141368-1.

Schropp, L., Wenzel, A., Kostopoulos, L. \& Karring, T. (2003) Bone healing and soft tissue contour changes following single-tooth extraction: a clinical and radiographic 12-month prospective study. Int J Periodontics Restorative Dent 23, 313-323.

Shi, B., Zhou, Y., Wang, Y. N. \& Cheng, X. R. (2007) Alveolar ridge preservation prior to implant placement with surgical-grade calcium sulfate and platelet-rich plasma: a pilot study in a canine model. Int J Oral Maxillofac Implants 22,656-665.

Sisti, A., Canullo, L., Mottola, M. P., Covani, U., Barone, A. \& Botticelli, D. (2012) Clinical evaluation of a ridge augmentation procedure for the severely resorbed alveolar socket: multicenter randomized controlled trial, preliminary results. Clin Oral Implants Res 23, 526-535. doi:10.1111/j.1600-0501.2011.02386.x.

Spinato, S., Galindo-Moreno, P., Zaffe, D., Bernardello, F. \& Soardi, C. M. (2014) Is socket healing conditioned by buccal plate thickness? A clinical and histologic study 4 months after mineralized human bone allografting. Clin Oral Implants Res 25, e120-126. doi:10.1111/clr.12073.

Stimmelmayr, M., Allen, E. P., Reichert, T. E. \& Iglhaut, G. (2010) Use of a combination epithelized-subepithelial connective tissue graft for closure and soft tissue augmentation of an extraction site following ridge preservation or implant placement: description of a technique. Int J Periodontics Restorative Dent 30, 375-381.

Stimmelmayr, M., Guth, J. F., Iglhaut, G. \& Beuer, F. (2012) Preservation of the ridge and sealing of the socket with a combination epithelialised and subepithelial connective tissue graft for management of defects in the buccal bone before insertion of implants: a case series. Br J Oral Maxillofac Surg 50, 550-555. doi:10.1016/j.bjoms.2011.09.014.

Tal, H. (1999) Autogenous masticatory mucosal grafts in extraction socket seal procedures: a comparison between sockets grafted with demineralized freezedried bone and deproteinized bovine bone mineral. Clin Oral Implants Res 10, 289-296.

Tallgren, A. (1972) The continuing reduction of the residual alveolar ridges in complete denture wearers: a mixed-longitudinal study covering 25 years. J Prosthet Dent 27, 120-132.

Tan, W. L., Wong, T. L., Wong, M. C. \& Lang, N. P. (2012) A systematic review of postextractional alveolar hard and soft tissue dimensional changes in humans. Clin Oral Implants Res 23 Suppl 5, 1-21. doi:10.1111/j.1600-0501.2011.02375.x. 
Thoma, D. S., Benic, G. I., Zwahlen, M., Hammerle, C. H. \& Jung, R. E. (2009) A systematic review assessing soft tissue augmentation techniques. Clin Oral Implants Res 20 Suppl 4, 146-165. doi:10.1111/j.1600-0501.2009.01784.x.

Thoma, D. S., Buranawat, B., Hammerle, C. H., Held, U. \& Jung, R. E. (2014) Efficacy of soft tissue augmentation around dental implants and in partially edentulous areas: a systematic review. J Clin Periodontol 41 Suppl 15, S77-91. doi: $10.1111 /$ jcpe. 12220 .

Thoma, D. S., Dard, M. M., Halg, G. A., Ramel, C. F., Hammerle, C. H. \& Jung, R. E. (2012) Evaluation of a biodegradable synthetic hydrogel used as a guided bone regeneration membrane: an experimental study in dogs. Clin Oral Implants Res 23, 160-168. doi:10.1111/j.1600-0501.2011.02217.x.

Thoma, D. S., Jung, R. E., Schneider, D., Cochran, D. L., Ender, A., Jones, A. A., Gorlach, C., Uebersax, L., Graf-Hausner, U. \& Hammerle, C. H. (2010) Soft tissue volume augmentation by the use of collagen-based matrices: a volumetric analysis. J Clin Periodontol 37, 659-666. doi:10.1111/j.1600-051X.2010.01581.x. Vignoletti, F., Matesanz, P., Rodrigo, D., Figuero, E., Martin, C. \& Sanz, M. (2012) Surgical protocols for ridge preservation after tooth extraction. A systematic review. Clin Oral Implants Res 23 Suppl 5, 22-38. doi:10.1111/j.16000501.2011.02331.x.

von Arx, T., Cochran, D. L., Hermann, J. S., Schenk, R. K., Higginbottom, F. L. \& Buser, D. (2001) Lateral ridge augmentation and implant placement: an experimental study evaluating implant osseointegration in different augmentation materials in the canine mandible. Int J Oral Maxillofac Implants 16, 343-354. 


\section{Table and Figure Legends}

Table 1.

Summary of the histomorphometric measurements at 4 weeks (A) and at 12 weeks (B) post implant placement. Mean, standard deviations (Std), and Medians are calculated with a confidence interval (CI) of 95\%; Q1=lower quartile; Q3=upper quartile. Estimated ridge profile (mm2; ERP); estimated regenerated area (mm2; ERA); percentage of regenerated area within estimated ridge profile (\%; ERA/ERP); percentages of new bone, lamellar bone, bone substitute material (BS) and non-mineralized tissue within ERP (\%); the bone-to-implant contact along the implant surface $(\mathrm{BIC} ; \%)$ on the buccal $\left(\mathrm{BIC}_{\mathrm{b}}\right)$ and lingual $\left(\mathrm{BIC}_{\mathrm{l}}\right)$ side; the first bone to implant contact $(\mathrm{mm}$; $\mathrm{fBIC})$ on the buccal $\left(\mathrm{fBIC}_{\mathrm{b}}\right)$ and lingual $\left(\mathrm{fBIC}_{\mathrm{l}}\right)$ side; the distance between the bone crest and the implant shoulder on the buccal $\left(\mathrm{B}_{\mathrm{b}}\right)$ and lingual $\left(\mathrm{B}_{1}\right)$ side. C. Statistical analysis with p-values.

Figure 1. Clinical pictures representing surgery 1 (extraction, root canal treatment, ridge preservation). A. preoperative view. B. Mesial roots of P3, P4 and M1 extracted and root canal treatments performed in distal roots of P3, P4 and M1. C. control x-ray after extraction and root canal treatment. D. Deproteinized bovine bone material with $10 \%$ collagen (DBBMC) has been placed in sites P4 and M1 (RP), coagulum in site P3. E. A collagen matrix has been sutured in RP sites (P3, M1).

Figure 2. Clinical pictures representing surgery 2 (implant placement and guided bone regeneration (GBR)). A. preoperative view. B. full-thickness flaps were reflected. C. all granulation tissue has been removed in sites P3 (SH) and M1 (RP2). No removal of Deproteinized bovine bone material with 10\% collagen (DBBM-C) in site P4 (RP1). D. implants were placed flush with the buccal bone crest. E. control x-ray after implant placement. F. Deproteinized bovine bone material granules (DBBM) is placed around the 
infrabony defects in groups SH (P3) and RP2 (M1). The buccal contour is not augmented. No GBR is applied in group RP1 (P4). G. the collagen membranes are immobilized in the apical region using resorbable pins and placed over the sites P3 (SH) and M1 (RP2). H. tension-free wound closure.

Figure 3.

Detailed schedule of surgeries and sacrifice dates.

Figure 4. a

a) Template used for the histomorphometric measurements:

- estimated ridge profile (ERP, in red); estimated regenerated area (ERA, in green); the first bone to implant contact (fBIC); level of the buccal bone crest (BC); level of the implant shoulder (IS); lamellar bone (LB); new bone (NB); all measurements were performed on the lingual (L) and buccal (B) side.

Figure 4. b-g

Histologic slides of the three groups 4 weeks (b-d) and 12 weeks (e-g) after implant placement. Levai-Laczkó staining and magnification of x20.

b Histological sample of group RP1

c Histological sample of group RP2

d Histological sample of group SH

e Histological sample of group RP1

f Histological sample of group RP2

g Histological sample of group SH 
RP1, ridge preservation without removal of the biomaterial; RP2, ridge preservation with removal of the biomaterial and GBR; $\mathrm{SH}$, site left for spontaneous healing and subsequent implant placement with GBR procedure. $\mathrm{LB}=$ lamellar bone; $\mathrm{NB}=$ new bone; $\mathrm{BS}=$ bone substitute material; $\mathrm{BC}=$ level of the buccal bone crest; $\mathrm{fBIC}=$ first bone to implant contact (buccal) 


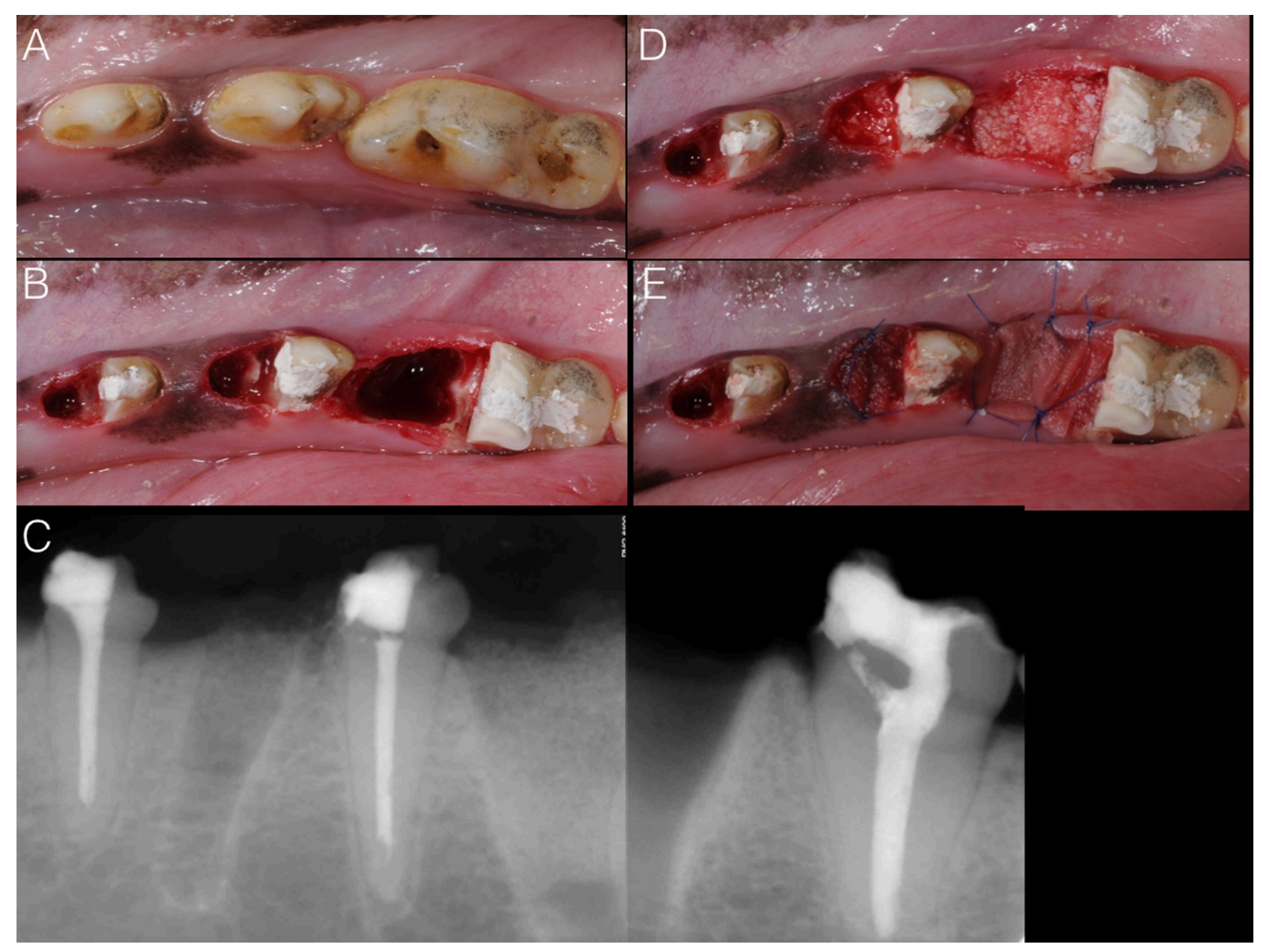

Figure 1 


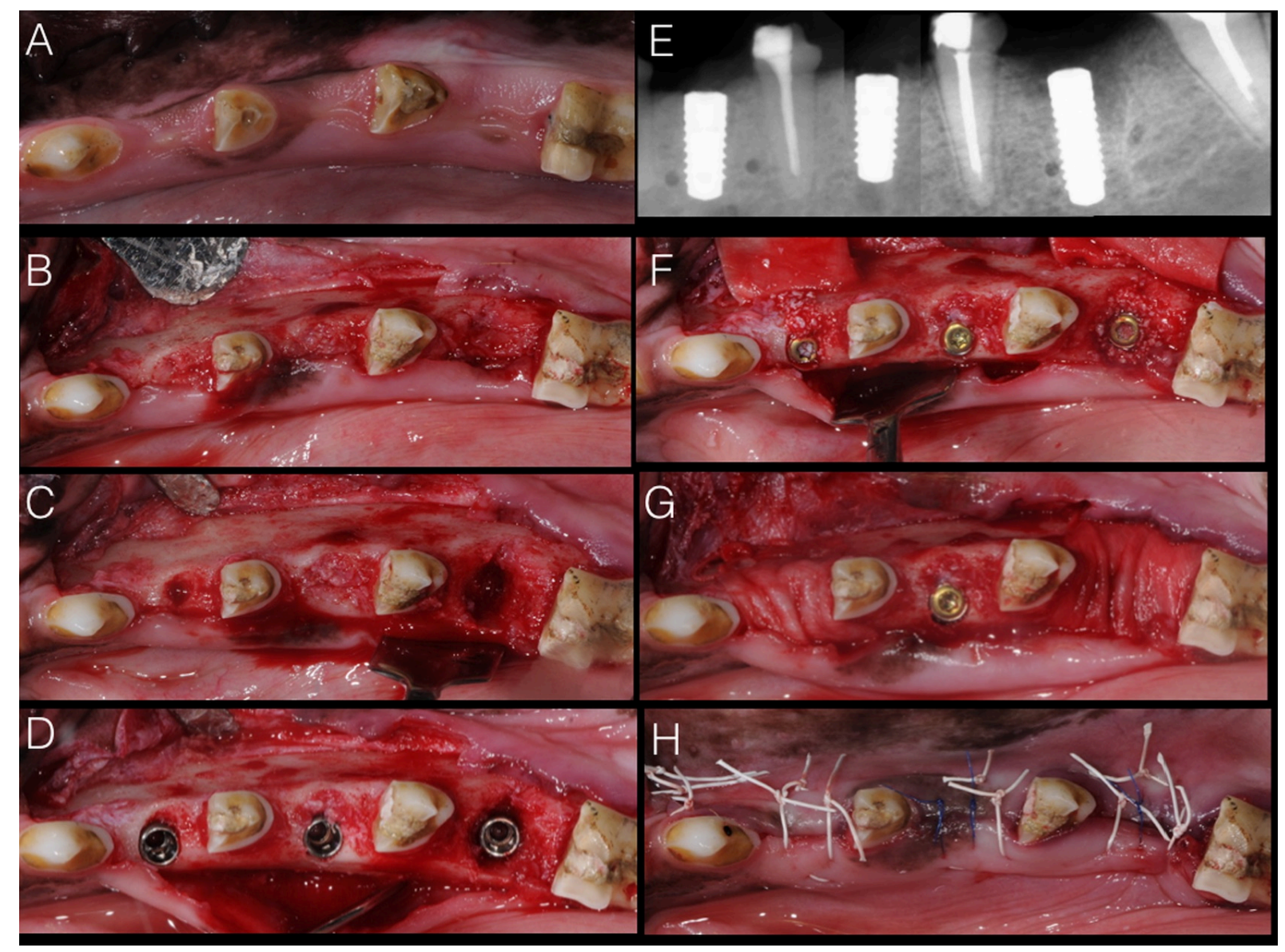

Figure 2

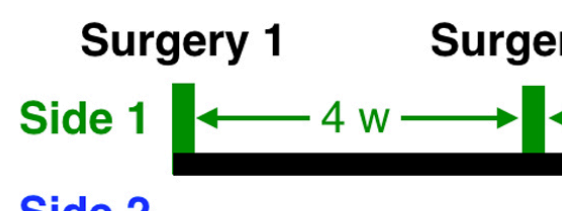

Side 2

\section{Surgery 1}

Sacrifice

Surgery 1:

Extraction / Ridge preservation

Surgery 2:

Devitalization

Implant placement

Figure 3 


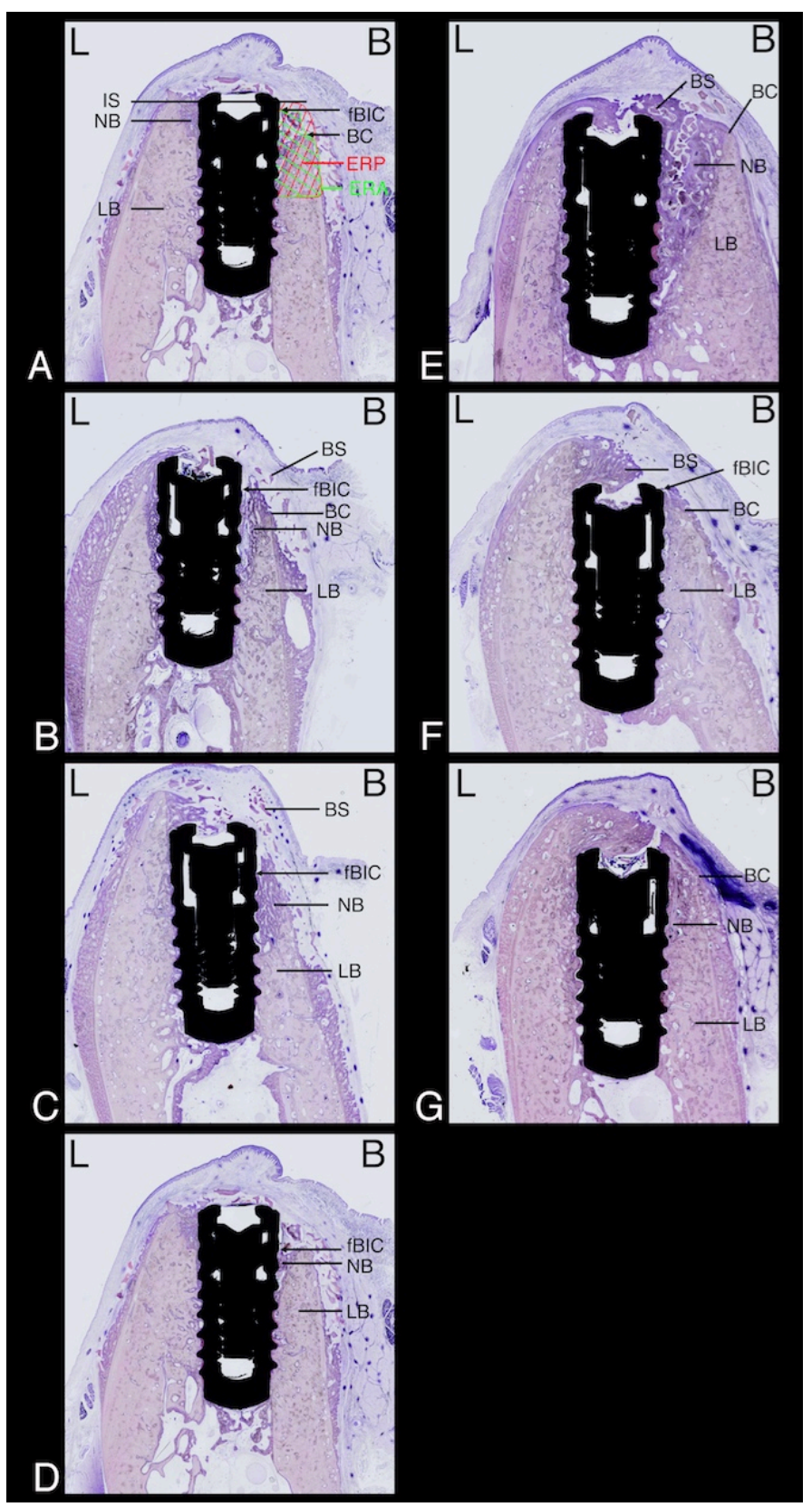

Figure 4 
Table 1A.

\begin{tabular}{|c|c|c|c|c|}
\hline Variable & & RP 1 & RP 2 & SH \\
\hline $\mathrm{B}_{\mathrm{b}}[\mathrm{mm}]$ & $\begin{array}{l}\text { Mean, Std } \\
\text { Q1, Median, Q3 }\end{array}$ & $\begin{array}{c}-0.83 \pm 2.73 \\
-2.19 ;-0.02 ; 0.94\end{array}$ & $\begin{array}{c}0.64 \pm 0.85 \\
0.17 ; 0.88 ; 1.15\end{array}$ & $\begin{array}{c}0.02 \pm 1.24 \\
-0.71 ; 0.42 ; 0.73\end{array}$ \\
\hline $\mathrm{fBIC}_{\mathrm{b}}[\mathrm{mm}]$ & $\begin{array}{l}\text { Mean, Std } \\
\text { Q1, Median, Q3 }\end{array}$ & $\begin{array}{c}1.84 \pm 2.06 \\
0.09 ; 1.34 ; 2.96\end{array}$ & $\begin{array}{c}1.94 \pm 2.00 \\
0.54 ; 1.41 ; 2.72\end{array}$ & $\begin{array}{c}1.25 \pm 1.59 \\
0.26 ; 0.79 ; 1.50\end{array}$ \\
\hline $\mathrm{B}_{1}[\mathrm{~mm}]$ & $\begin{array}{l}\text { Mean, Std } \\
\text { Q1, Median, Q3 }\end{array}$ & $\begin{array}{c}-2.35 \pm 2.04 \\
-3.52 ;-1.63 ;-0.86\end{array}$ & $\begin{array}{c}-0.75 \pm 0.80 \\
-1.27 ;-1.06 ;-0.37\end{array}$ & $\begin{array}{c}-0.73 \pm 0.76 \\
-1.09 ;-0.90 ;-0.34\end{array}$ \\
\hline $\mathrm{fBIC}_{1}[\mathrm{~mm}]$ & $\begin{array}{l}\text { Mean, Std } \\
\text { Q1, Median, Q3 }\end{array}$ & $\begin{array}{c}0.65 \pm 1.37 \\
0.00 ; 0.00 ; 0.62\end{array}$ & $\begin{array}{c}0.07 \pm 0.15 \\
0.00 ; 0.00 ; 0.08\end{array}$ & $\begin{array}{c}0.04 \pm 0.11 \\
0.00 ; 0.00 ; 0.00\end{array}$ \\
\hline $\mathrm{BIC}_{\mathrm{b}}[\%]$ & $\begin{array}{l}\text { Mean, Std } \\
\text { Q1, Median, Q3 }\end{array}$ & $\begin{array}{c}57.6 \pm 23.3 \\
36.8 ; 61.9 ; 71.3\end{array}$ & $\begin{array}{c}57.9 \pm 30.8 \\
41.1 ; 66.7 ; 76.1\end{array}$ & $\begin{array}{c}62.2 \pm 31.5 \\
42.1 ; 71.4 ; 85.7\end{array}$ \\
\hline $\mathrm{BIC}_{1}[\%]$ & $\begin{array}{l}\text { Mean, Std } \\
\text { Q1, Median, Q3 }\end{array}$ & $\begin{array}{c}71.1 \pm 12.4 \\
58.1 ; 76.4 ; 80.6\end{array}$ & $\begin{array}{c}67.36 \pm 30.54 \\
54.8 ; 81.5 ; 87.2\end{array}$ & $\begin{array}{c}70.0 \pm 14.7 \\
62.4 ; 71.1 ; 79.6\end{array}$ \\
\hline \multirow[t]{2}{*}{ ERP/ERA [\%] } & Mean, Std & $131.4 \pm 52.2$ & $105.7 \pm 36.0$ & $102.0 \pm 34.3$ \\
\hline & Q1, Median, Q3 & $100.0 ; 122.2 ; 176.9$ & $86.3 ; 114.6 ; 120.8$ & $83.7 ; 106.3 ; 120.6$ \\
\hline \multirow[t]{2}{*}{ New bone [\%] } & Mean, Std & $31.2 \pm 10.4$ & $38.1 \pm 11.8$ & $38.2 \pm 16.2$ \\
\hline & Q1, Median, Q3 & $21.5 ; 32.8 ; 39.3$ & $31.0 ; 34.7 ; 42.1$ & $26.9 ; 42.2 ; 48.4$ \\
\hline \multirow[t]{2}{*}{ Lamellar bone [\%] } & Mean, Std & $25.0 \pm 23.6$ & $24.7 \pm 16.0$ & $22.8 \pm 11.0$ \\
\hline & Q1, Median, Q3 & $10.8 ; 16.0 ; 36.2$ & $12.2 ; 22.5 ; 35.2$ & $12.0 ; 22.5 ; 31.4$ \\
\hline \multirow{2}{*}{$\begin{array}{l}\text { Bone substitute } \\
\text { material }[\%]\end{array}$} & Mean, Std & $7.1 \pm 5.6$ & $5.1 \pm 4.9$ & $6.4 \pm 5.3$ \\
\hline & Q1, Median, Q3 & $3.1 ; 6.5 ; 10.4$ & $0.4 ; 4.8 ; 9.1$ & $2.0 ; 6.1 ; 10.7$ \\
\hline \multirow{2}{*}{$\begin{array}{l}\text { Non-mineralized } \\
\text { tissue }[\%]\end{array}$} & Mean, Std & $36.7 \pm 17.1$ & $32.1 \pm 13.7$ & $32.7 \pm 8.6$ \\
\hline & Q1, Median, Q3 & $26.5 ; 37.6 ; 47.5$ & $21.8 ; 30.9 ; 42.2$ & $25.3 ; 32.4 ; 38.3$ \\
\hline
\end{tabular}


Table 1B.

\begin{tabular}{|c|c|c|c|c|}
\hline Variable & & RP 1 & RP 2 & SH \\
\hline \multirow[t]{2}{*}{$\mathrm{B}_{\mathrm{b}}[\mathrm{mm}]$} & Mean, Std & $0.22 \pm 2.72$ & $-0.70 \pm 1.44$ & $-0.63 \pm 1.21$ \\
\hline & Q1, Median, Q3 & $-1.74 ;-0.04 ; 1.27$ & $-2.18 ; 0.04 ; 0.29$ & $-1.15 ;-0.88 ; 0.48$ \\
\hline \multirow{2}{*}{$\mathrm{fBIC}_{\mathrm{b}}[\mathrm{mm}]$} & Mean, Std & $1.61 \pm 2.24$ & $0.60 \pm 0.79$ & $0.45 \pm 0.65$ \\
\hline & Q1, Median, Q3 & $0.00 ; 0.88 ; 2.33$ & $0.00 ; 0.16 ; 1.33$ & $0.00 ; 0.00 ; 0.98$ \\
\hline \multirow[t]{2}{*}{$\mathrm{B}_{1}[\mathrm{~mm}]$} & Mean, Std & $-0.98 \pm 0.91$ & $-1.53 \pm 0.96$ & $-1.36 \pm 0.57$ \\
\hline & Q1, Median, Q3 & $-1.67 ;-0.82 ;-0.14$ & $-2.31 ;-1.40 ;-0.80$ & $-1.70 ;-1.18 ;-0.93$ \\
\hline \multirow[t]{2}{*}{$\mathrm{fBIC}_{1}[\mathrm{~mm}]$} & Mean, Std & $0.93 \pm 2.17$ & $0.02 \pm 0.06$ & $0.00 \pm 0.00$ \\
\hline & Q1, Median, Q3 & $0.00 ; 0.00 ; 0.61$ & $0.00 ; 0.00 ; 0.00$ & $0.00 ; 0.00 ; 0.00$ \\
\hline \multirow[t]{2}{*}{$\mathrm{BIC}_{\mathrm{b}}[\%]$} & Mean, Std & $67.5 \pm 23.7$ & $78.5 \pm 14.5$ & $82.4 \pm 11.0$ \\
\hline & Q1, Median, Q3 & $56.7 ; 75.9 ; 80.9$ & $68.7 ; 75.4 ; 93.6$ & $77.8 ; 84.3 ; 89.0$ \\
\hline \multirow{2}{*}{$\mathrm{BIC}_{1}[\%]$} & Mean, Std & $74.0 \pm 20.4$ & $76.7 \pm 10.1$ & $71.1 \pm 22.2$ \\
\hline & Q1, Median, Q3 & $63.4 ; 83.6 ; 84.6$ & $67.9 ; 77.3 ; 84.5$ & $53.2 ; 72.6 ; 92.9$ \\
\hline \multirow[t]{2}{*}{ ERP/ERA [\%] } & Mean, Std & $92.8 \pm 49.0$ & $111.8 \pm 16.8$ & $98.1 \pm 49.0$ \\
\hline & Q1, Median, Q3 & $64.7 ; 105.5 ; 128.8$ & $100.0 ; 108.7 ; 122.0$ & $77.1 ; 104.8 ; 118.7$ \\
\hline \multirow[t]{2}{*}{ New bone [\%] } & Mean, Std & $49.0 \pm 24.2$ & $50.8 \pm 13.5$ & $52.0 \pm 11.3$ \\
\hline & Q1, Median, Q3 & $39.3 ; 56.7 ; 65.0$ & $47.7 ; 51.6 ; 60.4$ & $44.4 ; 52.3 ; 59.3$ \\
\hline \multirow[t]{2}{*}{ Lamellar bone $[\%]$} & Mean, Std & $13.2 \pm 17.7$ & $22.5 \pm 11.9$ & $19.0 \pm 13.4$ \\
\hline & Q1, Median, Q3 & $2.7 ; 7.7 ; 15.1$ & $15.4 ; 25.7 ; 31.1$ & $9.4 ; 19.3 ; 27.1$ \\
\hline \multirow{2}{*}{$\begin{array}{l}\text { Bone substitute } \\
\text { material [\%] }\end{array}$} & Mean, Std & $4.7 \pm 3.4$ & $3.6 \pm 3.0$ & $3.8 \pm 4.1$ \\
\hline & Q1, Median, Q3 & $1.4 ; 5.6 ; 7.5$ & $0.9 ; 2.9 ; 6.5$ & $0.3 ; 2.2 ; 8.0$ \\
\hline \multirow{2}{*}{$\begin{array}{l}\text { Non-mineralized } \\
\text { tissue }[\%]\end{array}$} & Mean, Std & $33.1 \pm 27.5$ & $23.2 \pm 14.0$ & $25.2 \pm 11.2$ \\
\hline & Q1, Median, Q3 & $21.4 ; 25.0 ; 28.5$ & $16.3 ; 17.3 ; 26.6$ & $16.8 ; 27.0 ; 34.2$ \\
\hline
\end{tabular}


Table 1C.

\begin{tabular}{|l|l|l|}
\hline Variable & 4 weeks & 12 weeks \\
\cline { 2 - 3 } & $\begin{array}{l}\text { Intergroup } \\
\text { comparison } \\
\text { (p-value) }\end{array}$ & $\begin{array}{l}\text { Intergroup } \\
\text { comparison } \\
\text { (p-value) }\end{array}$ \\
\hline $\mathrm{B}_{\mathrm{b}}[\mathrm{mm}]$ & 0.19791 & 0.72599 \\
\hline fBICb [mm] & 0.45228 & 0.36213 \\
\hline B1 [mm] & 0.27423 & 0.30221 \\
\hline fBICl [mm] & 0.38448 & 0.17712 \\
\hline BICb [\%] & 0.75882 & 0.33971 \\
\hline BICl [\%] & 0.84600 & 0.95152 \\
\hline ERP/ERA [\%] & 0.47571 & 0.89182 \\
\hline New bone [\%] & 0.37905 & 0.64982 \\
\hline Lamellar bone [\%] & 0.88659 & 0.16853 \\
\hline $\begin{array}{l}\text { Bone substitute } \\
\text { material [\%] }\end{array}$ & 0.70817 & 0.88426 \\
\hline $\begin{array}{l}\text { Non-mineralized } \\
\text { tissue [\%] }\end{array}$ & 0.73438 & 0.25318 \\
\hline
\end{tabular}

